\title{
Discouraging Elective Genetic Testing of Minors: A Norm under Siege in a New Era of Genomic Medicine
}

\author{
Laura Hercher \\ Sarah Lawrence College, Joan H. Marks Graduate Program in Human Genetics, Bronxville, \\ New York 10708, USA \\ Correspondence: Ihercher@sarahlawrence.edu
}

\begin{abstract}
Consistently, the field of genetic counseling has advocated that parents be advised to defer elective genetic testing of minors until adulthood to prevent a range of potential harms, including stigma, discrimination, and the loss of the child's ability to decide for him- or herself as an adult. However, consensus around the policy of "defer-when-possible" obscures the extent to which this norm is currently under siege. Increasingly, routine use of full or partial genome sequencing challenges our ability to control what is discovered in childhood or, when applied in a prenatal context, even before birth. The expansion of consumer-initiated genetic testing services challenges our ability to restrict what is available to minors. As the barriers to access crumble, medical professionals should proceed with caution, bearing in mind potential risks and continuing to assess the impact of genetic testing on this vulnerable population.
\end{abstract}

For decades, the field of genetic counseling has F articulated a single, consistent position on the genetic testing of minors: When possible, counselors should advise parents to defer genetic testing until adulthood. The phrase "when possible" functions as a caveat for medical necessity; genetic testing with an immediate medical purpose is noncontroversial. The rationale for discouraging elective genetic testing of minors was first described in the early 1990s and has been reaffirmed in more than 25 subsequent guidelines and position statements (Borry et al. 2006). In the year 1995 alone, consensus statements to that effect were adopted by six organizations of medical professionals, including the
American Medical Association (AMA Council on Ethical and Judicial Affairs 1995), the American Society of Human Genetics (ASHG), and the American College of Medical Genetics (ACMG) (The American Society of Human Genetics Board of Directors and The American College of Medical Genetics Board of Directors Rapid 1995). The 2017 position statement of the National Society of Genetic Counselors (NSGC) echoes the language of its predecessors (the Public Policy Committee of NSGC 2017):

The National Society of Genetic Counselors ... encourages deferring predictive genetic testing of minors for adult-onset conditions when results will not impact childhood medical management

Editors: Laura Hercher, Barbara Biesecker, and Jehannine C. Austin

Additional Perspectives on Genetic Counseling: Clinical Practice and Ethical Considerations available at

www.perspectivesinmedicine.org

Copyright (C) 2020 Cold Spring Harbor Laboratory Press; all rights reserved; doi: 10.1101/cshperspect.a036657

Cite this article as Cold Spring Harb Perspect Med 2020;10:a036657 
L. Hercher

or significantly benefit the child. Predictive testing should optimally be deferred until the individual has the capacity to weigh the associated risks, benefits, and limitations of this information, taking his/her circumstances, preferences, and beliefs into account to preserve his/her autonomy and right to an open future.

Today's genetic counselors are likely to be taught that the field discourages elective testing of minors as students. Bonnie Jeanne Baty, writing in A Guide to Genetic Counseling, strikes a note of concern about the motivation of parents who seek elective genetic testing for their children: "adults may coerce children into testing because of adult needs rather than appropriateness of testing for the child" (Uhlmann et al. 2009). Baty summarizes a representative ethical debate on the subject thusly: "they still recommend that the outcome (of the counseling process) preserve future autonomy by denying childhood testing... ." Similarly, Dawn Allain, writing in Ethical Dilemmas in Genetics and Genetic Counseling, describes an historical consensus that "unless medical intervention could benefit the minor, testing should be deferred until he or she reaches adult status" (Berliner 2015).

However, the consistent invocation of the "defer-when-possible" mantra masks the way in which this norm is under siege. To an extent, this reflects greater experience: A handful of early studies have tempered some of our worst fears about people's ability to handle the results of predictive genetic testing, although few of these studies examined children or adolescents (Green et al. 2009; Roberts et al. 2011). At the same time, the increasingly routine use of sequencing, which looks at great swaths of the genome rather than specific targets, challenges our ability to control what is discovered in childhood. Cellfree fetal DNA testing and other new developments in prenatal testing challenge our ability to control what is known about a child before he or she is born. Finally, the explosion of companies marketing genetic testing services outside of traditional clinical settings challenges our ability to draw an enforceable distinction between what is available to minors and what is available to adults.

\section{THE ARGUMENT AGAINST ELECTIVE GENETIC TESTING OF MINORS}

The ACMG/ASHG report "Points to Consider: Ethical, Legal and Psychosocial Implications of Genetic Testing in Children and Adolescents," published in 1995, lays out a medical and ethical basis for the recommendation to defer testing (The American Society of Human Genetics Board of Directors and The American College of Medical Genetics Board of Directors Rapid 1995). The standard used is the best interests of the child: "the primary goal of genetic testing should be to promote the well-being of the child." For the most part, "well-being" is defined as medical benefit, but the authors note that psychological benefits may be compelling as well, particularly in the case of a mature adolescent. And that benefit must be timely: "If the medical or psychosocial benefits of a genetic test will not accrue until adulthood, as in the case of carrier status or adult-onset diseases, genetic testing generally should be deferred."

The ACMG/ASHG paper identifies a number of potential harms that could result from the receipt of predictive genetic information at a young age. There is the possibility of discrimination by insurers, employers, teachers, or others. There is the question of stigma; the authors speculate that genetic information could alter a person's self-image or the expectations of those close to them. The authors suggest that genetic testing of minors may compromise their rights of autonomy and privacy. If tested as children, individuals lose the opportunity to decide for themselves as adults what they wish to know. They also lose the ability to control who has access to that information. Genetic testing is a lifelong commitment because what is known cannot be unknown; it is equally true that what is divulged cannot be undivulged.

Although the arguments against genetic testing of minors typically focus on adult-onset conditions, the emphasis on deferral of testing extends to childhood-onset conditions as well, although with less vehemence and more room for discretion. Pediatric cancer specialist Eric Kodish proposed the influential "rule of earliest onset" in 1999: Genetic testing should not occur 
before the age of earliest onset for the condition in question (Kodish 1999). This emphasis on immediate benefit has remained a touchstone and influenced practice guidelines (Saelaert et al. 2018).

Although Kodish is more definitive in his rule-making than some of his contemporaries (Wertz et al. 1994; Ross 2001), there is general agreement that parents who request genetic testing for their at-risk children before the age of earliest onset may well be acting on their own behalf and not in the best interests of their child (Wertz et al. 1994; Kodish 1999; Botkin et al. 2015; Lim et al. 2017). Wertz states tartly, "If no clear benefits exist, parents should restrain their desire to know" (Wertz et al. 1994).

Inherently, the push to defer decisions about testing to adulthood encompasses an unusual level of skepticism about the parents' ability or even their willingness to act in their child's best interests. Notably, the 1995 ACMG/ASHG guidelines place the burden of determining the minor's best interest on the providers and not the parents, directing providers to defer the choice to families or competent adolescents only "when the balance of benefits and harms is uncertain." This recommendation, a striking departure from the routine assumption that parents are the best arbiters of their child's interests, goes beyond the suggestion that providers discourage requests for elective genetic testing and advocates for them to refuse these requests if they disapprove: "A health care provider has no obligation to provide a medical service for a child or adolescent that is not in the best interest of the child or adolescent" (The American Society of Human Genetics Board of Directors and The American College of Medical Genetics Board of Directors Rapid 1995).

Seen in this light, the emphasis on deferring genetic testing of minors when possible is not simply a cautious default position-although it is that-but an assertion of a right so fundamental that it trumps the routine prerogatives of parents and guardians. The human right on which this argument rests is autonomy-specifically, the right of individuals to determine for themselves when and what genetic information they choose to receive: the right to know, but also (as it is called) "the right not to know." This claim in turn engenders what the 2017 NSGC position statement refers to as "the right to an open future." As described in 2019 by Garrett et al., philosopher Joel Feinberg first used the phrase "open future" to define a category of rights that children have but cannot exercise as minors. Parents and guardians, Feinberg argues, should not be allowed to act in such a way that their children's ability to make these choices is lost before it is gained (Garrett et al. 2019a). In genetics, the "right to an open future" guarantees that a child's right to make decisions about genetic testing for him or herself is not forestalled.

\section{THE RIGHT NOT TO KNOW}

The right to know and the right not to know are two sides of the same autonomy coin, so it is interesting and significant and perhaps unexpected that bioethicists and genetic clinicians have, historically speaking, chosen to emphasize the latter (Laurie 2014). Why? Why did UNESCO, in its 1998 Declaration on the Human Genome and Human Rights, feel it was necessary to stipulate "the right of every individual to decide whether or not to be informed of the results of genetic examination..." (UNESCO 1998)? Philosophically speaking, we may agree that people are free to remain uninformed as to the results of their own medical tests, but it hardly bears mentioning as a right. We do not debate whether or not people are adequately consented before being confronted with the results of their cholesterol tests or bone density scans or other common prognosticators of morbidity and mortality.

The significance of the right not to know in genetics hinges on the idea that because of the unique nature of genetic information, there are things a reasonable person might not wish to know. This was anticipated by ethicists and moral philosophers before genetic testing was widely available (Laurie 1999; Takala 1999; Wertz et al. 2003; Andorno and Laurie 2004), and the concern has been borne out in certain real-life scenarios in which the demand for testing has failed to meet expectations. An oft-cited exam- 


\section{Hercher}

ple of the phenomenon is predictive testing for Huntington's disease, in which surveys taken before a predictive test was available showed a high degree of interest among at-risk individuals, with much lower uptake once it was an existing rather than hypothetical alternative (Quaid and Morris 1993; Meiser and Dunn 2000). That said, Huntington's disease may not be the best model for predictive genetic testing overall, because as a lethal, adult-onset condition with essentially $100 \%$ penetrance and (to date) no way to treat or prevent it, it is the exception and not the rule.

But even in more typical scenarios, when genetics is a contributing and not determinative factor, our experience to date suggests that many people, adequately advised, choose not to know. They may be concerned that the results of testing will influence how other people view them or even how they view themselves. The theory of "genetic essentialism" posits that people will overvalue information on genetic attribution and fail to contextualize the genetic contribution to traits or risks even when environmental or other nongenetic factors are paramount (Dar-Nimrod and Heine 2011). A number of studies appear to bear this out (Dar-Nimrod et al. 2013; Lineweaver et al. 2014), including a recent report demonstrating that participants given sham genetic test results showed physiological changes in exercise capacity and appetite in line with what they believed to be their genetic predisposition (Turnwald et al. 2019).

Studies show that some people choose not to test based on concerns about privacy and/or genetic discrimination (Harris et al. 2005; Rothstein 2008). Although to date evidence for genetic discrimination among employers and insurers is thin on the ground (Rothstein and Anderlik 2001; Green et al. 2015), it does not change the fact that significant numbers of people have determined that genetic testing is not worth the perceived risk. Because circumstances change but genetic information does not, it is impossible to prove that their concerns for the future are unfounded.

What is true with regard to adults is even truer with regard to children. Adults may rationally decide they do not want to know about unavoidable bad things that will happen in the future; for a child, those same risks are that much farther away and harder to comprehend. As adults, they may have access to new information that makes testing more or less desirable. In addition, concerns have been voiced about whether or not minors are particularly vulnerable in terms of how the information affects their developing self-image, and whether or not they will be treated differently by their parents and others.

\section{PRENATAL TESTING}

Any concerns about genetic testing of minorsstigma, discrimination, loss of autonomy-are equally relevant to the question of prenatal genetic testing, because there is no mechanism by which information disclosed during pregnancy can be expunged at birth. However, practice in the prenatal setting is complicated by the possibility of elective termination.

Although it is possible that the best interests of the future child may be impinged upon by tests done before birth, it is unequivocally true that restricting prenatal testing denies parents the right to make decisions about whether or not to continue a pregnancy based on the best available information. Guidelines and positions statements from NSGC, ACMG, ASHG, and the American College of Obstetricians and Gynecologists (ACOG) all strongly advise that genetic counseling for parents considering prenatal genetic testing for adult disease include the potential negative implications of testing for themselves and their future child, should they choose to continue the pregnancy (American College of Obstetricians and Gynecologists 2008; Botkin et al. 2015; the Public Policy Committee of NSGC 2017). However, none of the organizations suggest that parents be denied the opportunity to test. The NSGC position statement published in 2017 states, "NSGC does not recommend prenatal genetic testing for known adult-onset conditions if pregnancy or childhood management will not be affected" (emphasis added here, not in original) (NSGC 2018).

In fact, there is always the possibility that pregnancy management will be affected, and it is not possible, or even rational, to suggest that 
expectant parents may know in advance how they will react to a positive test. Genetic counselors may discourage expectant parents from testing if they do not plan to abort an affected fetus, but restrictions on testing in the prenatal setting compromise the parents' reproductive rights. Therefore, tests that would not be offered to parents in the pediatric setting are available prenatally.

\section{THE RECOMMENDATION TO DEFER: OTHER CAVEATS AND EXCEPTIONS}

Despite widespread support, in principle, for discouraging elective genetic testing of minors, there are many agreed-upon exceptions to the rule. A quick overview of guidelines from 1995 to the present shows a steady growth of contextdependent caveats and exemptions. The ASHG/ ACMG guidelines written back in 1995 essentially divide genetic tests into two monolithic categories: those that do and those that do not provide a benefit during childhood. Carrier testing and adult-onset testing are mentioned as examples of the latter, but without any substantive exploration of the circumstances that make each of these settings unique (The American Society of Human Genetics Board of Directors and The American College of Medical Genetics Board of Directors Rapid 1995).

By contrast, a 2001 position paper on genetic testing from the American Association of Pediatrics (AAP 2001) goes into considerable detail on the ethical issues associated with carrier screening and predictive testing for adult-onset disorders, as well as newborn screening programs. Both carrier screening and predictive testing for adult-onset disease are identified as tests without immediate medical value for the child, and testing for these purposes is not recommended. In the case of adult-onset disease testing, pediatricians are advised to decline requests for testing from parents or guardians; whereas with carrier screening, there is a more nuanced recommendation that results obtained incidentally (e.g., through newborn screening) should be conveyed to parents, but that screening should not be instituted for the sole purpose of determining carrier status. In this distinction the subtleties are decisive; choosing not to get the information is quite different from choosing not to disclose the information.

Since those practice guidelines were published in 2001, genetic testing has grown rapidly, with a greater variety of tests being used in a greater variety of settings. The 2013 paper published jointly by the AAP and the ACMG reviews not only newborn screening, carrier screening, and predictive testing, but pharmacogenetic testing, histocompatibility testing, direct-to-consumer testing, and testing during the adoption process (Ross et al. 2013). In each case, the principles are the same, but context shapes the recommendations. With histocompatibility testing, for example, the AAP/ACMG guidelines suggest that the benefit to immediate family members creates such a conflict of interest that "a donor advocate or similar mechanism should be in place from the outset to avoid coercion and safeguard the interests of the child." In the case of adoption, the authors speculate that the best interests of an adoptable child with a known genetic risk may require that he or she is placed with "a family capable of and willing to accept the child's potential medical and developmental challenges... ." For this reason, the guidelines stipulate that predictive testing of a minor up for adoption may be ethically permissible. In one circumstance, the parents themselves cannot order testing without the oversight of a third party, whereas in the other, testing can be requested on behalf of prospective parents with no legal relationship at all.

Beyond what is reflected in guidelines and position statements, an increasing number of voices have resisted the idea that deferring elective genetic testing of minors is the preferable outcome and that medical providers are the best arbiters of the question rather than the families themselves (Wakefield et al. 2016; Lim et al. 2017; Garrett et al. 2019). In a 2016 commentary, Barbara Biesecker argues that families should be empowered to make their own decision about predictive genetic testing of minor children through a dynamic genetic counseling process that encourages them to consider the full range of potential outcomes in the context of their individual values, beliefs, and circum- 
stances. "Families should be encouraged to discuss the predictive testing of minors in genetic counseling and, after collaborative deliberation, be offered testing if that is the preferred outcome" (Biesecker 2016).

What this evolution of recommendations demonstrates is the importance of context in determining best practices in the genetic testing of minors. It is not just a question of who is being tested, but of how, when, where, and why the tests are being used. In this context-dependent analysis, the caveat of "when possible" in "defer testing when possible" has come to encompass a wider definition of value.

\section{ASSESSING VALUE}

Medical value - the ability to diagnose, treat, or prevent illness-is the most straightforward to assess and the least controversial, but there is also potential psychological value to performing genetic testing in minors. Testing may alleviate anxiety or allow a presymptomatic or at-risk individual (and their family) the opportunity to prepare. It can also inform life choices, such as financial planning or career decisions. Having more information about likely or potential future medical needs may be a factor in where a family lives or what home they choose. Exposure over time to the myriad ways in which genetic risk affects families has expanded our awareness of the complex dynamics involved in determining whether or not a test is useful.

Another way in which value can be assessed narrowly or widely is in how closely we hew to the idea that the sole beneficiary must be the minor child. Parental anxiety is a variable that merits consideration. Although genetic counselors have been advised not to view parental anxiety as a justification for testing (NSGC 2018), it may not help the child to ignore the needs of the parent. As Lainie Ross Friedman has pointed out, children's well-being is to some extent indistinguishable from that of their family (Ross 2002). However, if parental needs alone are the deciding factor in their desire to test, it is a weak case for testing the child and a strong argument for genetic counseling to explore their motivation and expectations.
It is an inherent complication of genomic medicine that the boundaries between patients and their families are porous. Genetic test results in minors may have implications for their relatives. Genetic testing of a child may inform reproductive decision-making for the parents or other family members. Parents may well argue that the loss of autonomy for a minor in these circumstances is less important than the value added for the family as a whole. Genetic tests of minors for late-onset disease may have immediate medical utility not for minors themselves but for their relatives. Whether or not this is a benefit depends on how the relative in question feels about receiving the information. With the introduction of exome sequencing into clinical practice, this once rare hypothetical situation has become an everyday question for genetic clinicians and is best discussed in the larger context of how exome and genome sequencing of minors alters the dynamics of practice.

\section{EXOME AND GENOME SEQUENCING OF MINORS}

One of the major drivers in the extraordinary growth in clinical genetic sequencing since 2009 is its use in the pediatric setting, in which exome testing has become a first-line approach for children with suspected genetic disease and/or developmental delay (Meng et al. 2017; Stark et al. 2017; Clark et al. 2018). Full or partial genome sequencing generates unprecedented amounts of data, raising issues of what to examine and what to report. Although some have argued that we are not compelled to analyze the excess information embedded in a clinical exome, just as we are not compelled to run every available blood test every time we phlebotomize a patient (Gliwa and Berkman 2013; Klitzman et al. 2013), 10 years of fractious debate over what to report suggests there is a perceived difference between tests not ordered and test results left unexamined in a file.

If the patient is a minor, the situation is particularly fraught. Though default settings for what is examined may differ, untargeted testing reduces our ability to pick and choose between tests with immediate benefit and those without. 
By design, clinical exome flags all variants with known medical implications. To opt out, we must actively seek to avoid getting the information, either by not interrogating those parts of the genome where it lies (if this is compatible with the medical purposes of the test) or by withholding the results, which, as we have seen in the earlier discussion of carrier screening, is an option that makes ethicists and clinicians uneasy.

Because having information in hand creates such a powerful incentive to disclose it, laboratories offering exome sequencing have chosen at times to eliminate the option. A 2012 version of Ambry's consent form for clinical exome sequencing gives adult patients the choice of whether or not to receive results in four categories: carrier disease status, later-onset disease risk, predisposition to increased risk for cancer, and early-onset disease risk not related to the reason for testing. For probands under 18, all four categories were blinded proactively. The test was configured not only to avoid passing along information to a clinician that normatively would not be shared with the parent or guardian, but even to avoid obtaining that information in the first place. This same assumption of the need for disclosure of any results motivated the AAP to advocate for return of carrier screening results to minors in cases in which the information was obtained incidentally, while discouraging its use as a rule (AAP 2001). Apparently, the risks and benefits of giving out secondary findings to minors are so finely balanced that ordering exome sequencing does not compel disclosure, and the labs and practitioners can safely ignore results that sit unexamined in a file, but having results - that is, having data that has been read by an informatics programtips the scales.

In 2013, the ACMG published the first guidelines for the return of secondary or incidental findings in which, for a limited number of genes in which the health risk was well-established, the medical implications were serious and an intervention was available, the group stipulated that results should be both sought and disclosed in all instances of clinical sequencing regardless of patient preferences (Green et al.
Genetic Testing of Minors: A Norm under Siege

2013). Although recognizing that their recommendations violated the norm of the "right not to know," the authors stated that "we felt clinicians and laboratory personnel have a fiduciary duty to prevent harm by warning patients and their families about certain incidental findings and that this principle supersedes concerns about autonomy...."

Controversially, the ACMG guidelines explicitly included tests done on minors, despite the fact that the diseases associated with the genes on the curated panel were largely adultonset. There were three parts to the rationale for this decision. First, that information on their future health could prove useful to minors. Second, that it would be unwieldy for laboratories to selectively reconfigure genetic sequencing reports for minors as the volume of testing increased. Third, that information found via testing of minors might be of immediate benefit to their adult family members.

The authors of the ACMG paper identify the potential to benefit relatives as an early-days effect, likely to disappear as genetic testing becomes more routine and widespread. Today, when clinical use of genetic testing is contingent on family or personal medical history, many carriers of risk-related variants will never be offered testing, and serendipity may be their only chance at finding out that they are at risk.

Despite these arguments, the recommendation to treat minors no differently than adults and the absence of a chance to opt out were identified as areas of concern by the ACMG membership, and in 2015 the college revised its guidelines to permit patients to opt out after counseling (Kalia et al. 2017), specifically noting that parents should be offered the opportunity to refuse analysis of genes unrelated to the indication for testing as a part of the informed consent process (Watson 2015).

This modification should not obscure the fact that the ACMG guidelines represent a significant shift in policy as regards genetic testing of minors. Although no longer mandatory, under these guidelines the option of testing minors for this limited set of adult-onset diseases is not only permissible but promoted as the default position. The 2013 ACMG working group 


\section{Hercher}

acknowledged and even embraced this as a break with prior practice. Earlier recommendations, the ACMG working group writes, were "inconsistent with the general practice of respecting parental decision-making about their child's health ..." (Green et al. 2013).

Although the ACMG guidelines refer to a limited, curated fraction of available information, the arguments they make about clinical utility and parental rights could be used to support broader disclosure of test results.

There are additional reasons why genetic counselors and laboratories might not wish to be the custodians of genetic information that does not get released to the family or the patient. There is liability associated with withholding information, if the results may have clinical value to family members now or the patient in the future. A plan that involves giving out the results at some later date assumes recontact, and neither the genetic counselor nor the family can reliably ensure that recontact occurs at the appropriate time, especially if that time is well in the future.

Further, patients do not have a legal right to demand all tests, but they do have a legal right to demand all test results. The Clinical Laboratory Improvement Amendments (CLIA) act of 1988 guaranteed patients (and their legal guardians) access to their medical records (1997), and an added rule passed in 2014 required laboratories to provide each person with their test results (HHS 2012). Under the "CLIA Program and Health Insurance Portability and Accountability (HIPAA) Privacy Rule: Patient Access to Test Reports," a motivated parent or guardian can obtain copies of any test report, even if it was not returned to the clinician. Does data need to be interpreted to be considered a result? The courts have yet to clarify that question (Guerrini et al. 2017), but what is clear is that exclusion violates the spirit of the rule change, which was intended to "provide individuals with a greater ability to access their health information, empowering them to take a more active role in managing their health and health care" (HHS 2012).

This push to "empower" people via their test results reflects a growing emphasis on data-driven and preventative care. These hopes lean heavily on genetics and genomics as a ve- hicle for predicting disease risk and personalizing care. Naturally, this vision is at odds with norms against genetic testing of minors. Although earlier positions presupposed that clinical utility was limited and circumscribed except when proven otherwise, the push to get data to people reflects a more optimistic view of the power of genomic information. At the same time, the logic of preventive medicine leads us to think about testing earlier, before conditions manifest, expanding the borderlines of "immediate" clinical utility. For medical problems like heart disease, diabetes, and obesity, it is hard to conceive of any programmatic intervention based on genetic risk assessment that is not optimized by starting in childhood. As a result, although it remains controversial, it is now commonplace for people to discuss sequencing infants at birth or even testing prenatally, and a number of NIH-funded research projects are examining the risks and benefits of each of these potentialities (Bianchi and Chiu 2018; Holm et al. 2018).

The temptation to test minors is likely to grow as we understand more about the health implications of genome-scale data. Clinical utility may increase rapidly or modestly, but the more we understand, the more we will have reason to use exome or genome sequencing, and the more likely it is that predictive information with and without clinical utility will be delivered as a package deal.

\section{EXOME AND GENOME SEQUENCING IN THE PRENATAL SETTING}

Prenatal screening today principally focuses on chromosome anomalies, although some forms of cell-free DNA testing provide information on microdeletions and copy number variants. However, proof-of-principle experiments have demonstrated that the technique can be used for anything up to and including genome sequencing (Klitzman et al. 2012; Mao et al. 2018). For a number of reasons, the move from targeted testing to untargeted testing would likely increase the number of children born with preexisting information on their genetic status. 
Targeted testing is both specific to a known disease or disease risk and rare, both of which make it amenable to counseling. If a man carries a known BRCA1 mutation and the couple wishes to test the fetus, the counselor can discuss the pros and cons with some degree of specificity. In many cases, the individual is already familiar with the condition because it runs in his or her family. But if the couple tests the fetus proactively for a catalog of pathogenic variants, practically, they cannot assess each one in advance to decide whether or not it would affect pregnancy management. One of the stated goals of genetic counseling for prenatal testing for adult-onset conditions is to steer parents away from testing if it would not change pregnancy management (NSGC 2018). Expanding the scope of what tests include will make this process less effective and push much of the decision-making to posttest counseling, when choosing not to have the information is no longer an option.

Untargeted tests can also be offered to a much wider audience than targeted testing, which was reserved for those at higher risk, and for that reason individual test takers have a lower prior probability of a positive result. Because there are more patients getting tested, it is harder to provide universal pretest counseling, and at the same time there is less motivation for it, because the average patient is more likely to come back with negative results.

Relying on genetic counseling to avoid return of results from prenatal testing that would not affect pregnancy management is a flawed strategy because pretest counseling is likely to be both less effective and more perfunctory as testing becomes increasingly routine. Realistically, if broader genetic testing becomes a standard part of prenatal care, for an increasing number of children, genetic information will be part of their medical record at birth.

\section{DIRECT-TO-CONSUMER GENETIC TESTING AND MINORS}

The use of direct-to-consumer genetic testing (DTC-GT) for minors is discouraged by organizations for genetic professionals (Caulfield et al. 2016). In fact, the potential to test minors is often cited as a part of the case against DTCGT in general (Botkin et al. 2015). However, no laws or regulations limit what DTC-GT is allowed for minors. Companies can choose to put a minimum age in their terms of service, but practically speaking that is hard to enforce for an online business model. In fact, some DTC-GT, such as tests claiming to identify athleticism or other "innate" abilities, are marketed specifically to parents with children in mind.

The menu of what is available via DTC without involvement of a medical professional changes frequently, but multiple tests include genes for susceptibility to Alzheimer's disease, breast cancer, Parkinson's disease, and other late-onset conditions. This includes the health risk test from 23andMe, in which customer care offers directions for registering children under 13 (customercare.23andme.com/hc/en-us/arti cles/202904710-Account-options-for-families), and the company's founder has spoken publicly about her decision to test her own children (Rochman and Wojcicki 2012). Ethicists and clinicians may have their doubts about whether or not this information should be available for minors, but the DTC-GT industry clearly believes that this is a question the market will answer.

One potential regulator of DTC-GT is the Food and Drug Administration (FDA), which draws a distinction between tests for susceptibility, which it calls genetic health risk tests, and those that may be diagnostic, which are subject to greater scrutiny and restriction (2017). In 2017, the FDA articulated a policy of distinguishing between the two, labeling those without immediate medical value as genetic health risk tests, and those with immediate medical value as diagnostic, although FDA Commissioner Scott Gottlieb conceded that striking the right balance was a challenge (FDA News Release 2017). There is a clear logic in restricting the use of DTC-GT for tests with immediate medical implications, in which misapplied or inaccurate results might misinform medical care. But ironically, this policy permits companies to market with no review or oversight, exactly the sort of predictive genetic testing that genetics professionals identified in the past as particularly inappropriate for minors. 
L. Hercher

\section{CONCLUSIONS}

The genetic counseling community has taken a clear stand against elective genetic testing of minors, although the position has long been subject to qualifications. Even the definition of elective testing has been up for debate, as it is not always easy to draw a clean line between tests with and without immediate medical value. Genes are pleiotropic and do not divide neatly into categories, meaning that testing for one reason can produce secondary findings. Medical value can be defined narrowly to include only information that changes clinical management in a direct and literal sense, or it can be defined broadly to include other types of well-being. Prohibiting testing is meant to protect the autonomy of the child, but it can also limit the autonomy of the parent or guardian, who is by law and tradition the principal decisionmaker when it comes to the best interests of their child. However, caveats and all, the idea that testing should be deferred when possible remains the norm in the field of clinical genetics.

However, although it may violate the beliefs and instincts of many genetic counselors, convergent trends suggest that genetic testing of minors may soon be commonplace. Rapid growth in the use of genome sequencing and better understanding of the role genetic variation plays in health and disease increase the number of health-related insights genetic testing might provide, making it harder to restrict genetic information as inappropriate for minors. Broad-based movements in support of preventive and personalized medicine favor the development of gene-based prevention strategies that are likely to lead us toward ever-earlier frontiers in genome sequencing, which not only includes but focuses on predictive information. Finally, with increased use of prenatal and direct-to-consumer testing, parents may relocate the question of what testing is permitted to a realm in which their authority is unchallenged.

There has never been a metric by which we could measure the amount of harm or benefit averted by deferring genetic testing to adulthood. Although it is clear the barrier to access is crumbling, it is not clear how much will be lost or gained as genetic testing of minors becomes commonplace. Medical professionals should proceed with some caution, bearing in mind potential risks and continuing to assess the impact of testing on this vulnerable population.

\section{REFERENCES}

AAP. 2001. Ethical issues with genetic testing in pediatrics. Pediatrics 107: 1451-1455. doi:10.1542/peds.107.6.1451

AMA Council on Ethical and Judicial Affairs. 1995. Testing children for genetic status. In Medical Ethics Reports, Vol. 6. AMA, Chicago.

American College of Obstetricians and Gynecologists. 2008. ACOG committee opinion No. 410: ethical issues in genetic testing. Obstet Gynecol 111: 1495-1502. doi:10 .1097/AOG.0b013e31817d252f

Andorno R, Laurie G. 2004. The right not to know: an autonomy based approach. J Med Ethics 30: 435-439.

Berliner J, ed. 2015. Ethical dilemmas in genetics and genetic counseling. Oxford University Press, New York

Bianchi DW, Chiu RWK. 2018. Sequencing of circulating cell-free DNA during pregnancy. $N$ Engl J Med 379: 464-473. doi:10.1056/NEJMra1705345

Biesecker BB. 2016. Predictive genetic testing of minors: evidence and experience with families. Genet Med 18: 763-764. doi:10.1038/gim.2015.191

Borry P, Fryns JP, Schotsmans P, Dierickx K. 2006. Carrier testing in minors: a systematic review of guidelines and position papers. Eur J Hum Genet 14: 133-138.

Botkin JR, Belmont JW, Berg JS, Berkman BE, Bombard Y, Holm IA, Levy HP, Ormond KE, Saal HM, Spinner NB, et al. 2015. Points to consider: ethical, legal, and psychosocial implications of genetic testing in children and adolescents. Am J Hum Genet 14: 133-138.

Caulfield T, Borry P, Toews M, Elger BS, Greely HT, McGuire A. 2016. Marginally scientific? Genetic testing of children and adolescents for lifestyle and health promotion. J Law Biosci 2: 627-644.

Clark MM, Stark Z, Farnaes L, Tan TY, White SM, Dimmock D, Kingsmore SF. 2018. Meta-analysis of the diagnostic and clinical utility of genome and exome sequencing and chromosomal microarray in children with suspected genetic diseases. NPH Genom Med 3: 16. doi:10.1038/ s41525-018-0053-8

Dar-Nimrod I, Heine SJ. 2011. Genetic essentialism: on the deceptive determinism of DNA. Psychol Bull 137: 800818. doi:10.1037/a0021860

Dar-Nimrod I, Zuckerman M, Duberstein PR. 2013. The effects of learning about one's own genetic susceptibility to alcoholism: a randomized experiment. Genet Med 15: 132-138. doi:10.1038/gim.2012.111

FDA News Release. 2017. Press Announcements-Statement from FDA Commissioner Scott Gottlieb, M.D., on implementation of agency's streamlined development and review pathway for consumer tests that evaluate genetic health risks. www.fda.gov/NewsEvents/Newsroom/ PressAnnouncements/ucm583885.htm 
Garrett JR, Lantos JD, Biesecker LG, Childerhose JE, Chung WK, Holm IA, Koenig BA, McEwen JE, Wilfond BS, Brothers K, et al. 2019. Rethinking the "open future" argument against predictive genetic testing of children. $\mathrm{Ge}$ net Med doi:10.1038/s41436-019-0483-4

Gliwa C, Berkman BE. 2013. Response to open peer commentaries on "Do researchers have an obligation to actively look for genetic incidental findings?" Am J Bioeth 13: W10-W11. doi:10.1080/15265161.2013.781470

Green RC, Roberts JS, Cupples LA, Relkin NR, Whitehouse PJ, Brown T, Eckert SL, Butson M, Sadovnick AD, Quaid KA, et al. 2009. Disclosure of APOE genotype for risk of Alzheimer's disease. N Engl J Med 361: 245-254. doi:10 .1056/NEJMoa0809578

Green RC, Berg JS, Grody WW, Kalia SS, Korf BR, Martin CL, Mcguire AL, Nussbaum RL, Daniel JMO, Ormond KE, et al. 2013. American College of Medical Genetics and Genomics ACMG recommendations for reporting of incidental findings in clinical exome and genome sequencing. Genet Med 15: 565-574. doi:10.1038/gim.2013.73

Green RC, Lautenbach D, McGuire AL. 2015. GINA, genetic discrimination, and genomic medicine. NEngl J Med 372: 397-399. doi:10.1056/NEJMp1404776

Guerrini CJ, McGuire AL, Majumder MA. 2017. Myriad take two: can genomic databases remain secret? Science 356: 586-587. doi:10.1126/science.aal 3224

Harris M, Winship I, Spriggs M. 2005. Controversies and ethical issues in cancer-genetics clinics. Lancet Oncol 6: 301-310. doi:10.1016/S1470-2045(05)70166-2

HHS. 2012. Part II Department of Health and Human Services SUPPLEMENTARY INFORMATION. Fed Regist 77: $1-58$.

Holm IA, Agrawal PB, Ceyhan-Birsoy O, Christensen KD, Fayer S, Frankel LA, Genetti CA, Krier JB, LaMay RC, Levy HL, et al. 2018. The BabySeq project: implementing genomic sequencing in newborns. BMC Pediatr 18: 225 . doi:10.1186/s12887-018-1200-1

Kalia SS, Adelman K, Bale SJ, Chung WK, Eng C, Evans JP, Herman GE, Hufnagel SB, Klein TE, Korf BR, et al. 2017. Recommendations for reporting of secondary findings in clinical exome and genome sequencing, 2016 update (ACMG SF v2.0): a policy statement of the American College of Medical Genetics and Genomics. Genet Med 19: 249-255. doi:10.1038/gim.2016.190

Klitzman JO, Snyder MW, Ventura M, Lewis AP, Qiu R, Simmons LE, Gammill HS, Rubens CE, Santillan DA Murray JC, et al. 2012. Noninvasive whole-genome sequencing of a human fetus. Sci Transl Med 4: $137 \mathrm{ra} 76$.

Klitzman R, Appelbaum PS, Chung W. 2013. Return of secondary genomic findings vs patient autonomy: implications for medical care. J Am Med Assoc 310: 369-370. doi:10.1001/jama.2013.41709

Kodish ED. 1999. Testing children for cancer genes: the rule of earliest onset. J Pediatr 135: 390-395. doi:10.1016/ S0022-3476(99)70142-3

Laurie G. 1999. In defence of ignorance: genetic information and the right not to know. Eur J Heal Law 6: 119-132. doi:10.1163/15718099920522730

Laurie G. 2014. Recognizing the right not to know: conceptual, professional, and legal implications. J Law Med Ethics 42: 53-63. doi:10.1111/jlme.12118
Genetic Testing of Minors: A Norm under Siege

Lim Q, McGill BC, Quinn VF, Tucker KM, Mizrahi D, Patenaude AF, Warby M, Cohn RJ, Wakefield CE. 2017. Parents' attitudes toward genetic testing of children for health conditions: a systematic review. Clin Genet 92 569-578. doi:10.1111/cge.12989

Lineweaver TT, Bondi MW, Galasko D, Salmon DP. 2014. Effect of knowledge of APOE genotype on subjective and objective memory performance in healthy older adults. Am J Psychiatry 171: 201-208. doi:10.1176/appi.ajp.2013 .12121590

Mao Q, Chin R, Xie W, Deng Y, Zhang W, Xu H, Zhang RY, Shi Q, Peters EE, Gulbahce N, et al. 2018. Advanced whole-genome sequencing and analysis of fetal genomes from amniotic fluid. Clin Chem 64: 715-725. doi:10.1373/ clinchem.2017.281220

Meiser B, Dunn S. 2000. Psychological impact of genetic testing for Huntingtons disease: an update of the literature. J Neurol Neurosurg Psychiatry 69: 574-578. doi:10 $.1136 /$ jnnp.69.5.574

Meng L, Pammi M, Saronwala A, Magoulas P, Ghazi AR, Vetrini F, Zhang J, He W, Dharmadhikari AV, Qu C, et al. 2017. Use of exome sequencing for infants in intensive care units ascertainment of severe single-gene disorders and effect on medical management. JAMA Pediatr 171: e173438. doi:10.1001/jamapediatrics.2017.3438

National Society of Genetic Counselors (NSGC). 2017. Genetic counseling of minors for adult-onset conditions. https://www.nsgc.org/p/bl/et/blogaid=860

National Society of Genetic Counelors (NSGC). 2018. Prenatal testing for adult-onset conditions. https://www.nsgc . org $/ \mathrm{p} / \mathrm{bl} / \mathrm{et} / \mathrm{blogaid}=1066$

Quaid KA, Morris M. 1993. Reluctance to undergo predictive testing: the case of Huntington disease. Am J Med Genet 45: 41-45. doi:10.1002/ajmg.1320450112

Roberts JS, Christensen KD, Green RC. 2011. Using Alzheimer's disease as a model for genetic risk disclosure: implications for personal genomics. Clin Genet 80: 407 414. doi:10.1111/j.1399-0004.2011.01739.x

Rochman BB, Wojcicki A. 2012. Test your DNA for diseases -no doctor required, pp. 10-13. Center for Genetics and Society, Berkeley, CA.

Ross LF. 2001. Ethical and policy issues in genetic testing. Pancreatology 1: 576-580. doi:10.1159/000055866

Ross LF. 2002. Predictive genetic testing for conditions that present in childhood. Kennedy Inst Ethics J 12: 225-244. doi:10.1353/ken.2002.0019

Ross LF, Saal HM, David KL, Anderson RR. 2013. Technical report: ethical and policy issues in genetic testing and screening of children. Genet Med 15: 234-245. doi:10 $.1038 /$ gim. 2012.176

Rothstein MA. 2008. Currents in contemporary ethics: GINA, the ADA, and genetic discrimination in employment. J Law Med Ethics 36: 837-840. doi:10.1111/j.1748720X.2008.00341.x

Rothstein MA, Anderlik MR. 2001. What is genetic discrimination, and when and how can it be prevented? Genet Med 3: 354-358. doi:10.1097/00125817-20010900000005

Saelaert M, Mertes H, De Baere E, Devisch I. 2018. Incidental or secondary findings: an integrative and patient-inclu- 


\section{Hercher}

sive approach to the current debate. Eur J Hum Genet 26: 1424-1431. doi:10.1038/s41431-018-0200-9

Stark Z, Schofield D, Alam K, Wilson W, Mupfeki N, Macciocca I, Shrestha R, White SM, Gaff C. 2017. Prospective comparison of the cost-effectiveness of clinical wholeexome sequencing with that of usual care overwhelmingly supports early use and reimbursement. Genet Med 19: 867-874. doi:10.1038/gim.2016.221

Takala T. 1999. The right to genetic ignorance confirmed. Bioethics 13: 288-293. doi:10.1111/1467-8519.00157

The American Society of Human Genetics Board of Directors and The American College of Medical Genetics Board of Directors Rapid. 1995. Points to consider: ethical, legal, and psychosocial implications of genetic testing in children and adolescents. Am J Hum Genet 57: 1233 1241.

Turnwald BP, Goyer JP, Boles DZ, Silder A, Delp SL, Crum AJ. 2019. Learning one's genetic risk changes physiology independent of actual genetic risk. Nat Hum Behav 3: 4856. doi:10.1038/s41562-018-0483-4

Uhlmann WR, Schuette J, Yashar B. 2009. A guide to genetic counseling. John Wiley \& Sons, Hoboken, NJ

UNESCO. 1998. UNESCO: Universal Declaration on the Human Genome and Human Rights. J Med Philos 23: 234-246.

Wakefield CE, Hanlon LV, Tucker KM, Patenaude AF, Signorelli C, McLoone JK, Cohn RJ. 2016. The psycholog- ical impact of genetic information on children: a systematic review. Genet Med 18: 755-762. doi:10.1038/gim .2015 .181

Watson MS. 2015. ACMG policy statement: updated recommendations regarding analysis and reporting of secondary findings in clinical genome-scale sequencing. Genet Med 17: 68-69. doi:10.1038/gim.2014.151

Wertz DC, Fanos JH, Reilly PR. 1994. Genetic testing for children and adolescents: who decides? J Am Med Assoc 272: 875-881. doi:10.1001/jama.1994.03520110055029

Wertz DC, Fletcher JC, Berg K. 2003. Review of ethical issues in medical genetics. Report of Consultants to WHO. WHO, Geneva. World Health Organization Human Genetetics Program: www.who.int

1997. Clinical Laboratory Improvement Amendments of 1988. Note that this document is provided as a convenience and includes excerpts from the full CLIA '88 Law to demonstrate the changes. This document does not represent the full context or intent of the law. 123: 2324.

2017. Federal Register: Medical Devices; Immunology and Microbiology Devices; Classification of the Genetic Health Risk Assessment System. Fed Regist federalregister.gov/d/2017-24159. www.federalregister.gov/documen ts/2017/11/07/2017-24159/medical-devices-immunolo gy-and-microbiology-devices-classification-of-the-gen etic-health-risk 


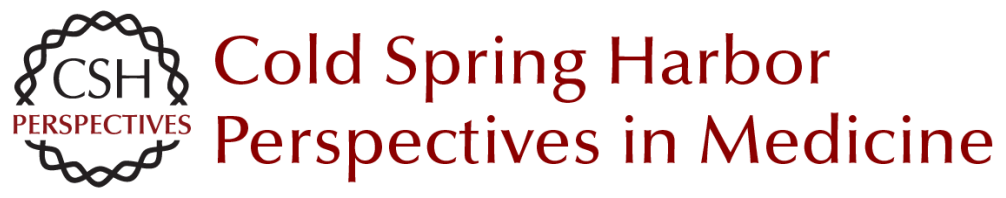

\section{Discouraging Elective Genetic Testing of Minors: A Norm under Siege in a New Era of Genomic Medicine}

\section{Laura Hercher}

Cold Spring Harb Perspect Med 2020; doi: 10.1101/cshperspect.a036657 originally published online September 23, 2019

\section{Subject Collection Genetic Counseling: Clinical Practice and Ethical Considerations}

\section{Genetic Risk Assessment in Psychiatry \\ Holly Landrum Peay}

Birds of a Feather? Genetic Counseling, Genetic Testing, and Humanism

$$
\text { Robert Resta }
$$

Bridging the Gap between Scientific Advancement and Real-World Application: Pediatric Genetic

Counseling for Common Syndromes and

Single-Gene Disorders Julie A. McGlynn and Elinor Langfelder-Schwind

Genetic Counseling, Personalized Medicine, and Precision Health

$$
\text { Erica Ramos }
$$

Tumor-Based Genetic Testing and Familial Cancer Risk

Andrea Forman and Jilliane Sotelo

\section{A Person-Centered Approach to Cardiovascular Genetic Testing Julia Platt}

Evidence-Based Genetic Counseling for

Psychiatric Disorders: A Road Map Jehannine C. Austin

Supporting Patient Autonomy and Informed Decision-Making in Prenatal Genetic Testing Katie Stoll and Judith Jackson
Impact of Emerging Technologies in Prenatal

Genetic Counseling

Blair Stevens

Genetic Counseling and Assisted Reproductive

Technologies Debra Lilienthal and Michelle Cahr

Evolving Roles of Genetic Counselors in the Clinical Laboratory Megan T. Cho and Carrie Guy

Psychological Issues in Managing Families with Inherited Cardiovascular Diseases Jodie Ingles

Informed Consent in the Genomics Era Shannon Rego, Megan E. Grove, Mildred K. Cho, et al.

Predictive Genetic Counseling for

Neurodegenerative Diseases: Past, Present, and

Future Jill S. Goldman

Cancer Genetic Counseling--Current Practice and Future Challenges Jaclyn Schienda and Jill Stopfer

Regulating Preimplantation Genetic Testing across the World: A Comparison of International Policy and Ethical Perspectives Margaret E.C. Ginoza and Rosario Isasi

For additional articles in this collection, see http://perspectivesinmedicine.cshlp.org/cgi/collection/ 